\title{
Ecclésiologie et hérésiologie (Moyen Âge, Temps modernes)
}

Auxerre, Centre d'études médiévales, 28-29 avril 2011

Dominique logna-Prat et Frédéric Gabriel

\section{(2) OpenEdition}

\section{Journals}

Édition électronique

URL : https://journals.openedition.org/cem/11993

DOI : 10.4000/cem.11993

ISSN : 1954-3093

Éditeur

Centre d'études médiévales Saint-Germain d'Auxerre

Édition imprimée

Pagination : 00

ISSN : 1623-5770

Référence électronique

Dominique logna-Prat et Frédéric Gabriel, « Ecclésiologie et hérésiologie (Moyen Âge, Temps

modernes) », Bulletin du centre d'études médiévales d'Auxerre / BUCEMA [En ligne], 15 | 2011, mis en ligne le 15 janvier 2013, consulté le 22 septembre 2022. URL : http://journals.openedition.org/cem/11993 ;

DOI : https://doi.org/10.4000/cem.11993

Ce document a été généré automatiquement le 22 septembre 2022.

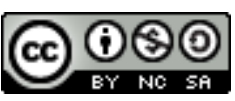

Creative Commons - Attribution - Pas d'Utilisation Commerciale - Partage dans les Mêmes Conditions 4.0 International - CC BY-NC-SA 4.0

https://creativecommons.org/licenses/by-nc-sa/4.0/ 


\section{Ecclésiologie et hérésiologie (Moyen Âge, Temps modernes)}

Auxerre, Centre d'études médiévales, 28-29 avril 2011

Dominique logna-Prat et Frédéric Gabriel

1 Dans quelle mesure l'institution ecclésiale génère-t-elle par nécessité propre les dissidences, "ses» dissidences? Le père Yves Congar, auquel l'une des journées du cycle les « Nouveaux horizons de l'ecclésiologie » a été consacrée en janvier 2009, a, en bonne partie, fondé son histoire de l'ecclésiologie sur le couple ecclésiologie/ hérésiologie, notant le fait avéré que les grands tournants ecclésiologiques sont, au Moyen Âge, le plus souvent concomitants de graves crises internes - par exemple le Grand schisme - ou de remises en cause venues de milieux « dissidents ». Les réflexions menées sur l'histoire de la notion d'orthodoxie ont depuis longtemps permis de prendre la mesure du jeu de miroir orthodoxie/hétérodoxie, générateur de doctrines et de normes. Les travaux accumulés depuis vingt ans sur l'hérésie médiévale comme phénomène de discours ont également mis en valeur le rôle de "révélateur » des dissidences, nécessaires antonymes d'une institution ecclésiale en mal de définition d'elle-même. En revenant sur le problème de la "qualification" et en étendant l'enquête jusqu'au temps par excellence de la tension dissidence/institution qu'est la Réforme, les historiens réunis pendant deux jours à Auxerre voulaient montrer la valeur heuristique de la triade institution/hérésie/réforme.

2 La réflexion préliminaire sur les problèmes de « qualification » a durablement structuré les débats autour de la valeur « historique » du couple ecclésiologie/hérésiologie. Fautil y voir un problème historique - l'émergence progressive d'un discours d'institution se forgeant par approximation au gré d'errements condamnés - ou plutôt un lien structurel renvoyant à la question des origines? Si oui, que faire des « témoins ", détenteurs de la vérité des origines et de la tradition qu'ils génèrent au fil de l'Histoire - une vérité et une tradition qui sont comme le «patrimoine » de l'Église ? D'autant que la thématique de la royauté du Christ a considérablement remodelé le rapport entre vérité et institution. La vérité n'est plus individuelle, psychologique, elle coïncide avec l'exercice d'un règne, à charge pour l'Église de protéger et d'administrer le dépôt de la foi qui 
témoigne de cette fondation. Cette institutionnalisation de la vérité permet tout naturellement de penser le pouvoir antihérétique de l'Église.

3 L'Ecclesia est une institution "qualifiante " au double sens du terme: elle qualifie la relation de caritas constitutive de la communauté chrétienne ; elle valide ou invalide la place et la qualité de ses membres : ainsi l'hérétique perd-il la « substance » du pouvoir. Par le biais de l'hérésiologie, l'église s'autorise à penser le lien au moment où il se dénoue et au sein d'un dispositif, qui n'affecte en rien l'unité qui la fonde. Mais, improbable congrégation d'utopistes nourris des logia du Christ, l'Ecclesia en vient ellemême à être qualifiée. Est-il vraiment possible de désigner une « essence » de l'Église, laquelle ne peut être définie que de façon descriptive, par un ensemble de termes toujours mouvant, termes propres - peuple de Dieu, sacerdoce, Temple... - ou métaphoriques (Jérusalem, Épouse, Mère...), infiniment renouvelés au cours du Moyen Âge, mais qui s'organisent en système avec la montée en puissance de l'Église romaine aux temps grégoriens. Pour autant, l'incertitude de la qualification demeure. Torquemada, au $\mathrm{Xv}^{\mathrm{e}}$ siècle, compte au moins seize qualifications possibles. Jean Huss distingue la «fausse » et la "vraie » Église, nommant la première "collegium » et la seconde, et elle seule, «Ecclesia». Les théoriciens du pouvoir pontifical à la fin du Moyen Âge soutiennent qu'il n'est d'Ecclesia que "romana» pour manifester la "visibilité » de l'Église, véritable économie du divin sur Terre - une visibilité impossible à l'Église universelle de type conciliaire. Mais l'institution est aussi celle des docteurs, qui repensent de l'intérieur la manière dont l'Église se qualifie ou des images qui jouent - à côté des discours orthodoxes - de leur plasticité d'expression et de la liberté que leur permettent les raccourcis temporels.

Le second axe des réflexions communes a tourné autour de la dialectique « ecclésiologie/hérésiologie ». Les polémiques suscitées par les doctrines cathares dès les années 1180-1200 cristallisent les débats autour d'une opposition " unité/dualisme » supposant de penser le Créé ou en termes d'opposition structurelle de principes, de mondes et d'êtres, ou bien sous la forme d'un dépassement de type hiérarchique, le multiple et ses oppositions accidentelles se subsumant dans l'Unité ultime. Se pose aussi la question de l'englobement de l'hérésiologie dans l'ecclésiologie sous trois formes possibles : l'hérésie comme instrument de la qualification ecclésiale - du type " est hérétique tout ce qui dévie du magistère »-; l'hérésie générale comme ressort de l'Ecclesia confondue avec la société chrétienne, qui n'a d'identité tangible que dans les limites de ce qu'elle rejette - par exemple le «nous » de la communauté sacramentelle à l'exclusion de... -; enfin, l'Église "hérétique", déviante, distinguée par les réformateurs de l'Église pure et sans tache des origines. Par phénomène de transfert institutionnel, cet "englobement " de l'hérésiologie dans l'ecclésiologie, va ensuite, dans le monde prémoderne, permettre de qualifier le royaume et le roi "très chrétien ", dont les instances de contrôle (du type du parlement), justifient la raison d'être des luttes contre les hérésies et les multiples figures de déviance propres à entacher la majesté étatique, mais nécessaires à sa révélation. À côté du pouvoir des clefs comme pouvoir pastoral plénier (contesté par Luther), s'élabore une véritable « ecclésiologie du royaume de France » au sein d'assemblées laïques qui s'emparent des questions doctrinales. Souveraineté et orthodoxie vont de concert.

Rappel du programme

1. Hérésie, dissidence : un problème de qualification

- E. coccia (GL. BRIGUGLIA, S. PIRON), Potestas doctrinalis : l'institution de la foi et la dissidence 
- F. GABRIEL (F. TRÉMOLIÈRES), Qualification de la communauté et autorité de la Tradition: l'histoire des dogmes comme construction ecclésiale $\left(\mathrm{XV}^{\mathrm{e}}-\mathrm{XVII}^{\mathrm{e}}\right.$ siècle)

7 2. L'hérésiologie comme moteur de l'ecclésiologie médiévale : un bilan

- D. IOGNA-PRAT, Problématique d'ensemble

- U. BRUNN (P. JIMÉNEZ), L'institution ecclésiale et la question du dualisme cathare

- D. RUSSO (A. TRIVELLONE), L'Église et ses dissidents en images

- Th. PRÜGL (A. MAIREY, É. ROSENBLIEH), Dissidences et renouvellements ecclésiologiques à la fin du Moyen Âge

8 3. Les Temps modernes comme tournant hérésiologique?

- T. LANGE, L'ecclésiologie du Royaume de France : l'hérésie devant le parlement de Paris dans les années 1520

-B. schmitz, Claves regni coelorum: le sens d'une métaphore entre hérésiologie et ecclésiologie

9 F. GABRIEL et D. IOGNA-PRAT, le mot de la fin

INDEX

Mots-clés : ecclésiologie, hérésiologie 